Universidad de Lima

Facultad de Ciencias Empresariales y Económicas

Carrera de Administración

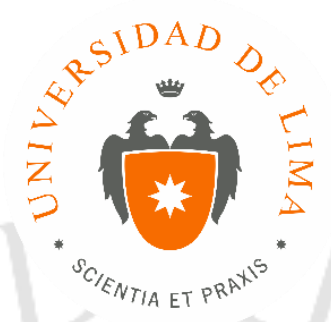

\title{
SUSTENTACIÓN DE CASO: PROPUESTA DE UN PLAN ESTRATÉGICO DEL INGRESO AL MERCADO PERUANO DE UNA EMPRESA DEL SECTOR FAST FASHION
}

Trabajo de suficiencia profesional para optar el Título Profesional de Licenciado en Administración

\section{Mariella Elvira Chichizola Fajardo}

Código 19850199

$$
\text { Lima - Perú }
$$

Noviembre de 2018 


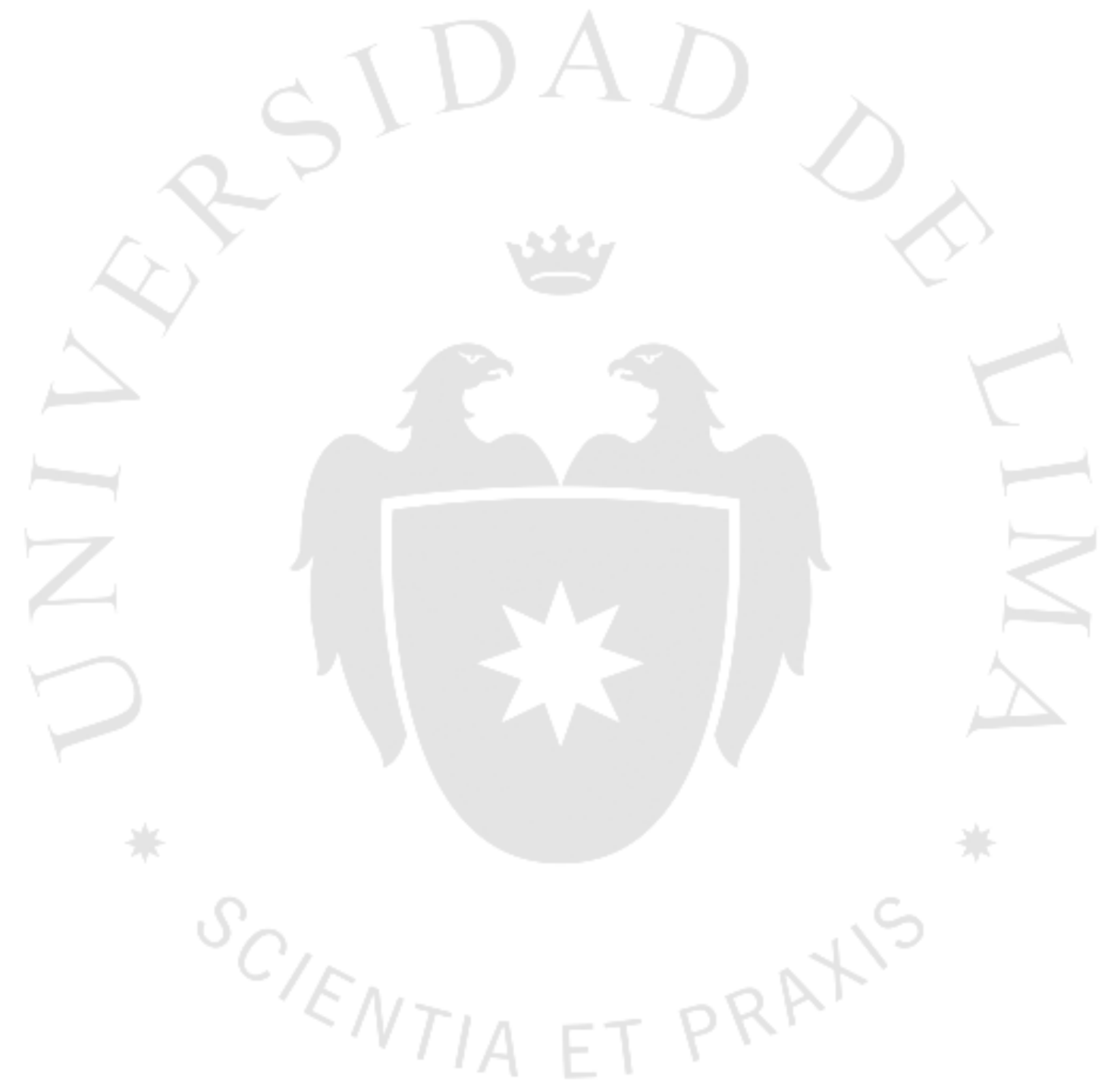


SUSTENTACIÓN DE CASO: PROPUESTA DE UN PLAN ESTRATÉGICO DEL INGRESO AL MERCADO PERUANO DE UNA EMPRESA DEL SECTOR FAST FASHION 


\section{TABLA DE CONTENIDO}

INTRODUCCIÓN ...............................................................................................1

CAPÍTULO I: DIAGNÓSTICO ESTRATÉGICO ............................................2

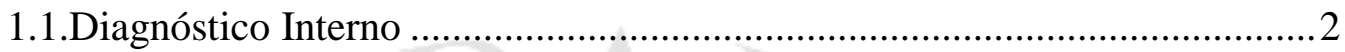

1.1.1 Análisis del Modelo de Negocio .........................................................

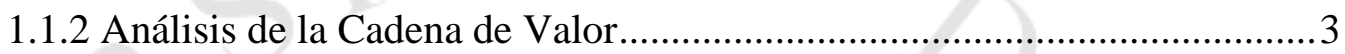

1.1.3 Definición y sustentación de las ventajas competitivas de la empresa y por

Unidad estratégica de negocio .5

1.1.4 Determinación y sustentación de las Fortalezas y Debilidades de la empresa y por Unidad estratégica de negocio ................................................6

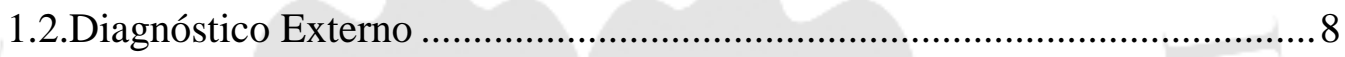

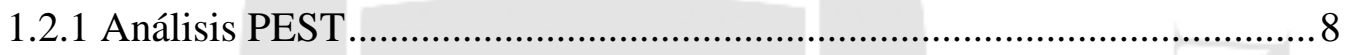

1.2.2 Análisis de las Fuerzas Competitivas del sector industrial...................... 10

1.2.3 Determinación y Sustentación de las Oportunidades y Amenazas........... 12

CAPITULO II: FORMULACIÓN DE LA ESTRATEGIA .......................14

2.1. Desarrollo y sustentación de la Matriz EFI ............................................... 14

2.2. Desarrollo y sustentación de la Matriz EFE ............................................... 15

2.3. Matriz de las Estrategias Genéricas ....................................................... 16

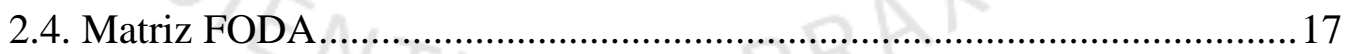

2.5. Definición y Sustentación de la Visión, Misión y Políticas ........................ 19

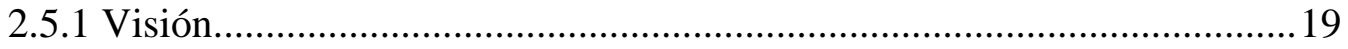

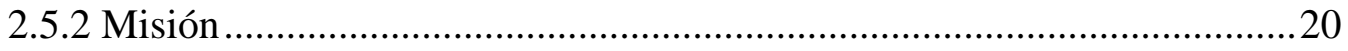

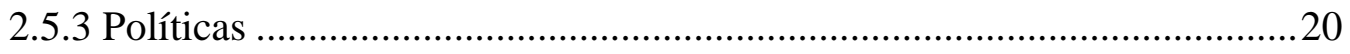

2.6. Definición de los Objetivos Estratégicos de la Empresa ...........................21

2.7. Redefinición o creación de nuevas UEN ................................................22 
2.8. Propuesta y sustentación de Estrategias en el ambiente Global, Corporativas, de Negocios y Funcionales. …...................................................22

2.8.1 Estrategia en el ambiente global.........................................................22

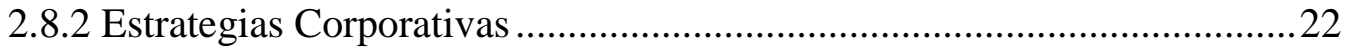

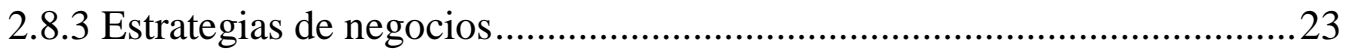

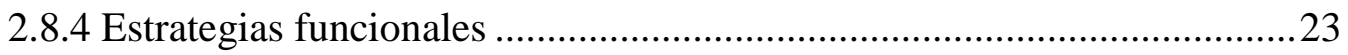

CAPÍTULO III: IMPLEMENTACIÓN ESTRATÉGICA............................26

3.1. Evaluación del rediseño o no rediseño de la estructura organizacional de la

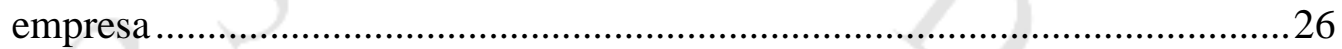

3.2. Propuesta de cambios para mejorar la implementación de estrategias en la

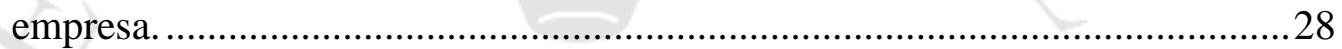

CAPÍTULO IV: CONTROL ESTRATÉGICO..............................................31

4.1. Diseño de un Mapa Estratégico de Control para la empresa ......................31

4.2. Desarrollo de un Cuadro de Mando Integral con un mínimo de 10 índices

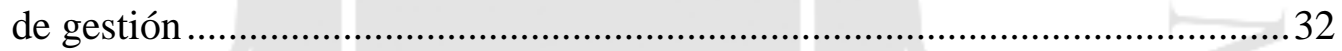

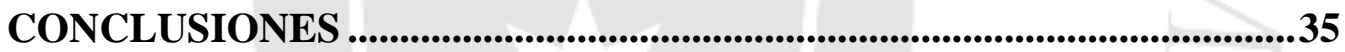

RECOMENDACIONES ......................................................................36

REFERENCIAS BIBLIOGRÁFICAS .......................................................39 


\section{ÍNDICE DE TABLAS}

Tabla 1.1 Evolución futura de factores del macro entorno ................................ 9

Tabla 2.1 Desarrollo de la Matriz EFI .............................................................. 14

Tabla 2.2 Desarrollo de la Matriz EFE .............................................................. 15

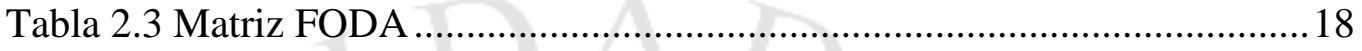

Tabla 4.1 Cuadro de mando integral para la empresa Fast Retailing en Perú ....32 


\section{ÍNDICE DE FIGURAS}

Figura 1.1 Cadena de valor de Porter para UNIQLO ........................................ 3

Figura 2.1 Estrategia genérica.................................................................. 17

Figura 3.1 Estructura Organizacional propuesta de Fast Retaling ....................28

Figura 4.1 Mapa Estratégico de Control para la empresa .................................. 31 


\section{INTRODUCCIÓN}

La industria de fast fashion o moda rápida ha tenido un crecimiento global importante en los últimos años impulsado por un concepto innovador que pone al alcance del consumidor alternativas de prendas que siguen tendencias de moda a un costo asequible y en períodos cortos de producción.

Esta realidad no ha sido ajena a nuestro país en donde ya contamos con tiendas líderes en fast fashion como lo son Zara y H\&M que tienen presencia en Lima y Provincias.

La entrada de estas empresas al mercado peruano ha producido una fuerte reacción de los competidores cercanos que son las tiendas por departamento (Saga y Ripley) quienes han desarrollado una serie de estrategias de defensa ante la caída de sus ventas y pérdida de participación de mercado.

El macro entorno económico del país es muy favorable ya que el crecimiento, en especial del sector retail, se mantiene entre los mejores de la región.

Los consumidores son conocedores y seguidores de marcas globales y acostumbran realizar compras que les permita acceso a la modernidad y mayor status.

En este contexto se evaluará, desde el punto de vista de consultor, la entrada al mercado peruano de la empresa japonesa global Fast Retailing a través de la marca UNIQLO que brinda una oferta de confecciones básicas de gran calidad e innovación.

En el presente informe se realizará el análisis empresarial y el plan estratégico a fin de proponer los objetivos, estrategias, estructura organizacional y los aspectos a tener en cuenta para una exitosa implementación y adecuado control de las operaciones de la empresa en nuestro país. 


\section{CAPÍTULO I: DIAGNÓSTICO ESTRATÉGICO}

\subsection{Diagnóstico Interno}

\subsubsection{Análisis del Modelo de Negocio}

El modelo de la principal línea de negocio de la empresa (UNIQLO) será analizado utilizando el lienzo de modelo de negocio de Osterwalder.

Creemos que la mejor manera de describir un modelo de negocio es dividirlo en nueve módulos básicos que reflejen la lógica que sigue una empresa para conseguir ingresos. Estos nueve módulos cubren las cuatro áreas principales de un negocio: clientes, oferta, infraestructura y viabilidad económica. El modelo de negocio es una especie de anteproyecto de una estrategia que se aplicará en las estructuras, procesos y sistemas de una empresa. (Osterwalder y Pigneur, 2011, p. 15).

Los componentes que se consideran son los siguientes:

Propuesta de Valor: Se ofrecen productos textiles básicos, duraderos, elaborados con materiales de alta calidad y con tecnología innovadora a precios asequibles.

Relaciones con los clientes: Se brinda un excelente servicio al cliente en su experiencia de compra y en la post venta constituyéndose como un pilar fundamental de su modelo de negocio.

Segmentos de mercado: Alta segmentación. Se ofrece de manera masiva ropa informal para damas, caballeros y niños a nivel global.

Canales: El canal es directo dado que se dedica al diseño, producción y venta minorista de sus productos a través de sus tiendas físicas y online.

Actividades clave: Se consideran las que generan ventajas competitivas como investigación y desarrollo, compras, producción, ventas, recursos humanos y responsabilidad social.

Recursos clave: Los constituyen los materiales de alta calidad, el personal entrenado, la disposición de fondos para inversión y crecimiento, la tecnología. 
Asociaciones clave: Con diseñadores importantes, proveedores y fábricas de confecciones de China.

Estructura de costes: Reducida en comparación con la competencia. Esto debido a que luego de diseñar y fabricar vende su marca propia directamente como minorista.

Fuente de Ingresos: Venta de ropa a nivel nacional y global.

\subsubsection{Análisis de la Cadena de Valor}

La cadena de valor nos permite identificar las actividades que realiza la empresa, sus ventajas competitivas y el valor percibido por el cliente.

El término cadena de valor se refiere a la idea de que una compañía es una cadena de actividades que transforman los insumos en productos que valoran los clientes. El proceso de transformación implica una serie de actividades primarias y de apoyo que agregan valor al producto. (Hill y Jones, 2009, p. 83)

Las actividades de la cadena de valor de Porter para el negocio principal de la empresa (UNIQLO) se muestran a continuación:

Figura 1.1

Cadena de valor de Porter para UNIQLO

\begin{tabular}{|l|c|c|c|}
\hline Infraestructura & \multicolumn{1}{|c|}{ I+D } & Sistemas \\
\hline RRHH & \multicolumn{1}{|c|}{ Marketing } & Compras \\
Diseño & $\begin{array}{l}\text { Logística de } \\
\text { ingreso } \\
\text { Operaciones / } \\
\text { Producción }\end{array}$ & Venta \\
\hline
\end{tabular}

Nota: Hill y Jones (2009)

Fuente: Elaboración propia

Como actividades de soporte o apoyo se identifican las siguientes:

- Infraestructura: Constituida por el equipo directivo que desde la matriz brinda las pautas para la gestión estratégica y funcionamiento de sus empresas a nivel global. 
- Recursos Humanos: Cuentan con programas de formación y línea de carrera para encargados de tiendas, así como un centro especializado (Fast Retailing Management and Innovation Center, FRMIC) para la formación de líderes. Cultura organizacional consolidada.

- Investigación y desarrollo: Fuerte orientación a la investigación y desarrollo a fin de asegurar la permanente innovación de los productos en cuanto a calidad del material y diseño de las prendas.

- Marketing: Fuerte actividad publicitaria a través de medios de comunicación tradicionales y digitales. Apuestan por publicidad de impacto que genere recordación en los clientes. Un ejemplo de ello es la publicidad realizada en Barcelona en la que se refuerza el uso de sus prendas para aprovechar los momentos especiales de la vida (ELLE España, 2017) o la que explica las bondades de su línea ultra ligth down (UNIQLO UK, 2015).

- Sistemas: Potencial por desarrollar en big data, ventas online y transformación digital que le permita mejorar eficiencia y el valor para el cliente así como identificar nuevas oportunidades de negocio.

- Compras: Gran poder de negociación con los proveedores dadas las compras de grandes volúmenes de material. Adquisición de material de alta calidad.

Dentro de las actividades primarias de la cadena de valor de UNIQLO se tiene:

- Diseño: Realizado en forma propia en alianza con diseñadores especializados. Se presenta como primaria debido a su relevancia en el modelo de negocio.

- Logística de ingreso: Recepción de materiales y control de inventarios. Manejo de precios para favorecer que el inventario se agote.

- Operaciones/ Producción: Fabricación con economías de escala y de ubicación a través de empresas asociadas. Apertura de tiendas de gran formato.

- Venta: Experiencia de venta de calidad centrada en satisfacer al cliente.

- Post venta: Orientada a satisfacer requerimientos y devoluciones del cliente, así como recibir sus comentarios para mejorar los productos. 


\subsubsection{Definición y sustentación de las ventajas competitivas de la empresa y por Unidad estratégica de negocio}

“Una compañía tiene una ventaja competitiva sobre sus rivales cuando su rentabilidad es mayor que el promedio de las otras empresas que operan en la industria." (Hill y Jones, 2009, p. 77).

\subsubsection{Ventajas competitivas de Fast retailing}

Operaciones/ Producción

Calidad superior: Para sus diferentes marcas nacionales y globales la empresa brinda prendas de calidad que satisfacen a los clientes de los segmentos a los que atiende.

Eficiencia operacional superior: A través de economías de escala que logra en la producción de marcas propias y la adquisición de material o productos terminados por grandes volúmenes para sus diferentes unidades estratégicas de negocio.

Venta

Superior satisfacción del cliente: El servicio al cliente es uno de los pilares de la filosofía de la empresa y es considerado componente fundamental del negocio.

Infraestructura

Innovación superior: Creación del FRMIC centro de formación de futuros líderes en habilidades gerenciales y en los principios de gestión de la empresa.

Integración del desarrollo de la sociedad como parte de su misión.

Cultura organizacional consolidada lo cual favorece la innovación, implementación de estrategias y gestión del cambio.

1.1.3.2. Ventajas competitivas de la principal unidad estratégica de negocio (UNIQLO)

Operaciones/ Producción

Calidad superior: Prendas de alta calidad en sus materiales y tecnología de fabricación lo cual constituye un elemento diferenciador. Según Odriozola (2017) indica: 
Tres tecnologías principales articulan sus colecciones: Airism (que consigue mantener el cuerpo seco en condiciones de alta humedad), HeatTech (una potente solución para combatir el frío, formada por cuatro tipos de hilo combinados que absorben la humedad que generamos y la transforman en calor) y Ultra Light Down (que reduce increíblemente el peso de la prenda. (párr. 4)

Eficiencia operacional superior: Economías de escala por la fabricación de prendas y adquisición de material en grandes volúmenes. Economía de ubicación en China con mano de obra barata y cercana al mayor mercado de la empresa.

Venta

Superior satisfacción del cliente: Excelente servicio al cliente en su experiencia de compra lo cual incluye personal atento y preparado, tienda limpia, rápido proceso de pago, compra on line. Organización orientada al cliente.

\section{Post - venta}

Superior satisfacción del cliente: Brinda políticas flexibles de devoluciones, servicio de arreglos de prendas, acercamiento al cliente para conocer su opinión sobre los productos y ofrecer cupones de descuentos.

Investigación y desarrollo

Innovación superior: Centros dedicados a la investigación y desarrollo a fin de asegurar la permanente innovación. Cuentan con sedes en New York, Tokio, París y Milán. Realiza también innovación en canales como por ejemplo la máquina dispensadora de prendas Uniqlo To Go ubicada en varios aeropuertos de Estados Unidos (KPIX CBS SF Bay Area, 2018)

\subsubsection{Determinación y sustentación de las Fortalezas y Debilidades de la empresa y por Unidad estratégica de negocio}

\subsubsection{Empresa Fast Retailing}

Fortalezas

- Presencia internacional y respaldo económico. 
- Sistema de valores y principios compartidos que constituyen el alma y la cultura de la empresa. Promueve la innovación y facilita la implementación de las estrategias.

- Inversión y formación del personal clave dado que buscan crear un vínculo de largo plazo y compromiso con sus empleados encargados de tienda y con los futuros directivos.

- Sólido programa de responsabilidad social que se constituye como un diferenciador muy ligado al negocio y a la misión de la empresa.

- Poder de negociación con proveedores de todo el mundo para adquisiciones de material de calidad a bajo costo.

- Alianzas con número determinado de fábricas para la confección de sus prendas de marca propia a las que brinda asistencia técnica lo cual asegura la calidad y economías de escala.

\section{Debilidades}

- Red de tiendas limitado en comparación con la competencia.

- Proceso de planeamiento estratégico con oportunidades de mejora lo cual se sustenta en acciones de negocio fallidas, metas optimistas, entre otros.

- Sistema de gestión centralizado en el dueño no evidenciándose una línea de sucesión definida a ese nivel.

- La estructura organizacional no está de acuerdo a sus planes de expansión y crecimiento.

- No cuenta con capitalización bursátil al nivel de los competidores.

\subsubsection{Principal unidad estratégica de negocio (UNIQLO)}

Fortalezas

- Marca propia y concepto del uso de su ropa bien posicionado a nivel nacional y global. Existe adecuada publicidad y se evidencia lealtad de los clientes.

- Producción de prendas de calidad y con economías de escala la cual considera un equipo especializado para supervisión de calidad y asesoría técnica.

- Diseño propio, simple, práctico y combinable, que se realiza en alianza con diseñadores dedicados. 
- Adecuado proceso de venta y post venta orientado al cliente lo cual se constituye como uno de los diferenciadores de UNIQLO.

- Investigación de nuevas tecnologías de confección y utilización de materiales.

Debilidades

- Canal de Ventas online representa el 3\% de sus ventas. No se aprovecha su potencialidad ni se evidencian planes para su desarrollo.

- Red de tiendas UNIQLO limitada en comparación con la competencia y concentrado en Asia.

- Vende más que la competencia por pie cuadrado pero su margen es menor lo cual indica que su gestión operativa presenta oportunidades de mejora.

- La velocidad de apertura de tiendas es menor en comparación con la competencia.

\subsection{Diagnóstico Externo}

\subsubsection{Análisis PEST}

Para realizar el análisis del macro entorno se identificará los factores relevantes que lo afectan y se determinará si constituyen Oportunidades que se deben aprovechar o amenazas que se deben minimizar o contrarrestar.

"El propósito fundamental de este análisis es identificar las oportunidades y amenazas estratégicas que existen en el ambiente operativo de la organización que pueden influir en la forma en que se intente alcanzar la misión.” (Hill y Jones, 2009, p. 16).

\subsubsection{Factor Político- Legal. -}

Incertidumbre política en el país debido a crisis en el gobierno por casos de corrupción. Impacta en la estabilidad política necesaria para promover inversiones. (Amenaza)

Creación del gremio Retail y distribución. Podría tener un impacto positivo ya que promueven intereses comunes en beneficio del sector. (Oportunidad)

\subsubsection{Factor económico. -}

Excelente posición del Perú como unos de los países emergentes más atractivos para invertir en el sector retail (Oportunidad) 
Crecimiento económico sostenido y por consiguiente del nivel adquisitivo lo cual tendrá un impacto en la demanda de los productos (Oportunidad)

Potencial de mercado disponible para crecimiento de retail en provincias (Oportunidad)

Estancamiento de venta de ropa por coyuntura económica por baja inversión. Se estima sin embargo que esta tendencia será revertida en el corto plazo (Amenaza)

Plan de incremento en la cantidad de malls en los próximos años lo cual facilitaría alquiler de tiendas para la empresa (Oportunidad)

Baja inversión en obras públicas genera menor consumo interno, es una situación que podría mantenerse en el corto plazo (Amenaza)

\subsubsection{Factor Socio Cultural. -}

Consumidores con estilo de vida moderno son conocedores de las marcas globales de fast fashion y acostumbrados a hacer compras en Malls (Oportunidad)

Consumidores de provincia con expectativas de llegada de la modernidad en retail. (Oportunidad)

Mayor hábito de hacer turismo en el país contribuye al crecimiento del sector retail. (Oportunidad)

\subsubsection{Factor Tecnológico. -}

Tendencia a la transformación digital y omnicanalidad lo cual permitirá ampliar cobertura del mercado y una mejor experiencia para el cliente a través de mayor tecnología e integración de servicio en sus canales (Oportunidad).

\subsubsection{Evolución futura de factores}

Determinaremos, en base al análisis realizado, la evolución futura de los factores en el corto, mediano y largo plazo.

Tabla 1.1

Evolución futura de factores del macro entorno

Evolución futura de factores del macro entorno

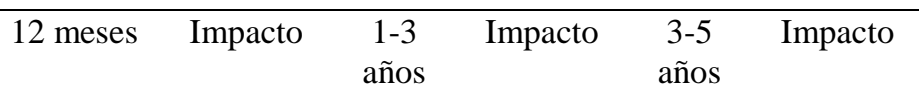




\begin{tabular}{|c|c|c|c|c|c|c|}
\hline Factor político - Legal & $\mathrm{Neg}$ & A & $\mathrm{Neg}$ & $\mathrm{A}$ & Pos & $\mathrm{O}$ \\
\hline Incertidumbre política en el país & Pos & $\mathrm{O}$ & Pos & $\mathrm{O}$ & Pos & $\mathrm{O}$ \\
\hline \multicolumn{7}{|l|}{ Creación gremio Retail y distribución } \\
\hline \multicolumn{7}{|l|}{ Factor económico } \\
\hline Posición del Perú atractivo sector retail & Pos & $\mathrm{O}$ & Pos & $\mathrm{O}$ & Pos & $\mathrm{O}$ \\
\hline Crecimiento económico & Pos & $\mathrm{O}$ & Pos & $\mathrm{O}$ & Pos & $\mathrm{O}$ \\
\hline Potencial de mercado en provincias & Pos & $\mathrm{O}$ & Pos & $\mathrm{O}$ & Pos & $\mathrm{O}$ \\
\hline Estancamiento de venta de ropa & $\mathrm{Neg}$ & A & Pos & $\mathrm{O}$ & Pos & $\mathrm{O}$ \\
\hline Incremento de malls & Pos & $\mathrm{O}$ & Pos & $\mathrm{O}$ & Pos & $\mathrm{O}$ \\
\hline Baja inversión en obras públicas & $\mathrm{Neg}$ & A & Pos & $\mathrm{O}$ & Pos & $\mathrm{O}$ \\
\hline \multicolumn{7}{|l|}{ Factor social- cultural } \\
\hline Consumidor moderno e informado. & Pos & $\mathrm{O}$ & Pos & $\mathrm{O}$ & Pos & $\mathrm{O}$ \\
\hline Expectativa de llegada a provincias & Pos & $\mathrm{O}$ & Pos & $\mathrm{O}$ & Pos & $\mathrm{O}$ \\
\hline Hábito de hacer turismo en el país & Pos & $\mathrm{O}$ & Pos & $\mathrm{O}$ & Pos & $\mathrm{O}$ \\
\hline \multicolumn{7}{|l|}{ Factor tecnológico } \\
\hline $\begin{array}{l}\text { Tendencia a transformación digital y } \\
\text { omnicanalidad }\end{array}$ & Pos & $\mathrm{O}$ & Pos & $\mathrm{O}$ & Pos & $\mathrm{O}$ \\
\hline
\end{tabular}

Nota: Hill y Jones (2009)

Fuente: Elaboración propia

La mayoría de factores se mantendrán en el tiempo. Sin embargo, existen algunos factores para los que se evidencia una mejora en el mediano plazo como son el estancamiento de venta de ropa y la baja inversión en obras públicas sustentado en el crecimiento económico proyectado para el país para los próximos años.

En el caso de incertidumbre política del país se estima que en largo plazo se visualiza un panorama más estable apoyado con las próximas elecciones generales.

\subsubsection{Análisis de las Fuerzas Competitivas del sector industrial}

Para realizar el análisis se utilizará el modelo de las cinco fuerzas de Porter el cual permite determinar el atractivo de un sector según su rentabilidad y la intensidad de la competencia. "Porter sostiene que cuanto más intensa sea cada fuerza, más limitada será la capacidad de las compañías establecidas para aumentar los precios y obtener más ganancias." (Hill y Jones, 2009, p. 45).

\subsubsection{Intensidad de la rivalidad entre las compañías establecidas en una industria}

Se analizarán bajo esta fuerza los siguientes componentes: 
Estructura de la industria. - La industria es consolidada ya que existen pocas empresas grandes (tiendas por departamento y fast fashion) que poseen la mayor participación del mercado. En este caso la rivalidad es alta. (Amenaza)

Crecimiento de la demanda. - La demanda en el país está en crecimiento, sobretodo del sector retail, por tanto, la rivalidad es baja. (Oportunidad)

Diferenciación. - La diferenciación es alta dado que la industria ofrece desde prendas básicas hasta seguidoras de tendencia de la moda para diversos segmentos. La rivalidad es baja. (Oportunidad)

Costo del cambio. - El costo de cambiar hacia otras opciones de ropa es bajo por tanto la rivalidad es alta. (Amenaza)

Barreras de salida. - Son altas debido al tamaño de las empresas. Implicaría tener que cancelar contratos de alianzas estratégicas. Rivalidad alta (Amenaza)

Se concluye que la rivalidad de la industria es alta. (Amenaza)

\subsubsection{Riesgo de entrada de nuevos competidores}

Se analizarán las barreras de entrada a la industria. "El riesgo de que entren competidores potenciales es una función de la altura de las barreras que impiden la entrada, es decir, de los factores que elevan los costos para que las compañías ingresen en una industria." (Hill y Jones, 2009, p. 46).

Lealtad a la marca. - Existe por parte de los consumidores identificación con las marcas extranjeras globales ya que su uso y preferencia les otorga status social. Un nuevo competidor global sería bien recibido por los clientes.

Economías de Escala. - Constituye una barrera relevante ya que pone en desventaja a competidores que no estén en capacidad de lograr reducción de costos por altos volúmenes de producción y de adquisiciones al por mayor.

Requisitos de Capital. - Un nuevo competidor necesitará una fuerte inversión de capital para producción, marketing, materias primas, investigación y desarrollo, tecnología, entre otros.

Fuerte reacción de los actores actuales. - Al tratarse de una industria consolidada las reacciones de los actores influyen de manera importante en los demás. En específico 
la industria ya viene tomando medidas ante el ingreso de las fast fashion como son marcas propias, posicionamiento de tiendas, entre otros.

En conclusión, si bien las barreras de entrada son altas para los competidores, la posición global de Fast Retailing le permite poder manejarlas con éxito en su mayoría y entrar a competir en el mercado peruano. (Oportunidad)

\subsubsection{Poder de negociación de los compradores}

El poder de negociación de los compradores en este caso es alto dado que existen otras opciones a las cuales pueden acudir para satisfacer su necesidad. Tiene la posibilidad de comprar en varias empresas a la vez. (Amenaza)

\subsubsection{Poder de negociación de los proveedores}

En la industria se cuenta con múltiples proveedores que abastecen material estándar o diferenciado a las empresas o también productos terminados. Las grandes empresas compran altos volúmenes lo cual le otorga una ventaja frente al proveedor. El poder de negociación de los proveedores en este caso es bajo. (Oportunidad)

\subsubsection{Existencia de productos sustitutos}

Existen productos sustitutos en la medida que las diferentes empresas ofrecen confecciones similares que difieren en estilo y calidad pero que podrían ser cambiadas por los consumidores sin incurrir en mayores costos. (Amenaza)

\subsubsection{Determinación y Sustentación de las Oportunidades y Amenazas}

En base al análisis del macro y micro entorno se identifican las principales Oportunidades y amenazas.

\subsubsection{Oportunidades}

- Excelente posición económica del Perú para invertir en el sector retail lo cual se sustenta en el crecimiento sostenido durante dos décadas, la integración comercial a través de tratados de libre comercio, entre otros.

- Potencial de mercado disponible para crecimiento de consumo retail en provincias.

- Plan de incremento en la cantidad de malls en los próximos años. 
- Consumidores con estilo de vida moderno, conocedores de las marcas globales y con aspiración a mayor status.

- Barreras de entrada altas para nuevos competidores, lo que se constituye como oportunidad para Fast Retailing dada su sólida posición para ingresar al mercado peruano.

- Transformación digital y omnicanalidad que deben ser aprovechadas para desarrollar ventajas competitivas de innovación y satisfacción del cliente superiores.

\subsubsection{Amenazas}

- Incertidumbre política en el país debido a crisis en el gobierno lo cual afecta el crecimiento económico y las inversiones extranjeras.

- Alta rivalidad en la industria lo cual limita la obtención de mayores ganancias.

- Baja inversión en obras públicas genera menor consumo interno

- Reacción de los competidores actuales requiere de mayores esfuerzos y estrategias para mejorar participación de mercado.

- Bajo costo de cambio hacia otros productos. 


\section{CAPITULO II: FORMULACIÓN DE LA ESTRATEGIA}

\subsection{Desarrollo y sustentación de la Matriz EFI}

Tabla 2.1

Desarrollo de la Matriz EFI

\begin{tabular}{|c|c|c|c|}
\hline Matriz EFI & Valor & Clasificación & Valor Ponderado \\
\hline \multicolumn{4}{|l|}{ Fortalezas } \\
\hline Presencia internacional y respaldo económico & 0.07 & 4 & 0.28 \\
\hline $\begin{array}{l}\text { Marca propia y concepto de uso bien } \\
\text { posicionados }\end{array}$ & 0.06 & 4 & 0.24 \\
\hline Producción de prendas de calidad & 0.06 & 4 & 0.24 \\
\hline Diseño propio, simple y práctico & 0.06 & 4 & 0.24 \\
\hline $\begin{array}{l}\text { Adecuado proceso de venta y post venta } \\
\text { orientado al cliente }\end{array}$ & 0.06 & 4 & 0.24 \\
\hline $\begin{array}{l}\text { Poder de negociación con proveedores de todo } \\
\text { el mundo }\end{array}$ & 0.06 & 4 & 0.24 \\
\hline $\begin{array}{l}\text { Investigación de nuevas tecnologías de } \\
\text { confección y utilización de materiales }\end{array}$ & 0.06 & 4 & 0.24 \\
\hline Alianzas con fábricas de confección & 0.05 & 4 & 0.20 \\
\hline $\begin{array}{l}\text { Inversión y formación del personal de tienda y } \\
\text { directivo }\end{array}$ & 0.05 & 3 & 0.15 \\
\hline Sólido programa de responsabilidad social & 0.05 & 3 & 0.15 \\
\hline $\begin{array}{l}\text { Sistema de valores y principios compartidos } \\
\text { que constituyen el alma y la cultura de la } \\
\text { empresa }\end{array}$ & 0.05 & 3 & 0.15 \\
\hline \multicolumn{4}{|l|}{ Debilidades } \\
\hline Canal de Ventas online poco desarrollado & 0.06 & 1 & 0.06 \\
\hline $\begin{array}{l}\text { Red de tiendas limitado en comparación con } \\
\text { competencia }\end{array}$ & 0.06 & 1 & 0.06 \\
\hline Proceso de planeamiento estratégico & 0.05 & 2 & 0.10 \\
\hline $\begin{array}{l}\text { La estructura organizacional no está de acuerdo } \\
\text { a sus estrategias }\end{array}$ & 0.05 & 2 & 0.10 \\
\hline Gestión operativa con oportunidades de mejora & 0.04 & 2 & 0.08 \\
\hline $\begin{array}{l}\text { No cuenta con capitalización bursátil al nivel de } \\
\text { los competidores. }\end{array}$ & 0.04 & 1 & 0.04 \\
\hline $\begin{array}{l}\text { La velocidad de apertura de tiendas es menor en } \\
\text { comparación con la competencia. }\end{array}$ & 0.04 & 2 & 0.08 \\
\hline Sistema de gestión centralizado en el dueño & 0.03 & 2 & 0.06 \\
\hline
\end{tabular}


Nota: David (2003)

Fuente: Elaboración propia

"Esta herramienta para la formulación de la estrategia resume y evalúa las fortalezas y las debilidades principales en las áreas funcionales de una empresa, al igual que proporciona una base para identificar y evaluar las relaciones entre estas áreas." (David, 2003, p. 149).

Para la matriz de evaluación del factor interno se identifica un resultado ponderado de 2.95 , por encima del promedio de 2.5 , lo cual nos indica que la empresa tiene una sólida posición para aprovechar sus fortalezas y mitigar sus debilidades.

Se ha considerado mayor valor a las fortalezas referentes a los pilares más importantes de la empresa por los cuales es reconocida y obtiene ventajas competitivas.

La mayoría de ellas obtienen una clasificación de 4 (fortaleza mayor).

En el caso de las debilidades si bien se observa que la mayoría son menores, es necesario centrar esfuerzos para contrarrestar sobre todo las que ponen a la empresa en desventaja como son el canal online, red de tiendas y la capitalización bursátil.

\subsection{Desarrollo y sustentación de la Matriz EFE}

Tabla 2.2

Desarrollo de la Matriz EFE

\begin{tabular}{|c|c|c|c|}
\hline Matriz EFE & Valor & Clasificación & Valor Ponderado \\
\hline \multicolumn{4}{|l|}{ Oportunidades } \\
\hline $\begin{array}{l}\text { Excelente posición del Perú para invertir en } \\
\text { sector retail. }\end{array}$ & 0.15 & 4 & 0.60 \\
\hline $\begin{array}{l}\text { Potencial de mercado para crecimiento de retail } \\
\text { en provincias }\end{array}$ & 0.07 & 3 & 0.21 \\
\hline $\begin{array}{l}\text { Plan de incremento en la cantidad de malls en } \\
\text { los próximos años }\end{array}$ & 0.11 & 4 & 0.44 \\
\hline $\begin{array}{l}\text { Consumidores conocedores de las marcas } \\
\text { globales y con aspiración a mayor status }\end{array}$ & 0.11 & 4 & 0.44 \\
\hline $\begin{array}{l}\text { Barreras de entrada altas para nuevos } \\
\text { competidores }\end{array}$ & 0.06 & 3 & 0.18 \\
\hline Transformación digital y omnicanalidad & 0.10 & 2 & 0.20 \\
\hline \multicolumn{4}{|l|}{ Amenazas } \\
\hline $\begin{array}{l}\text { Incertidumbre política en el país debido a crisis } \\
\text { en el gobierno. }\end{array}$ & 0.08 & 3 & 0.24 \\
\hline
\end{tabular}




\begin{tabular}{llll}
\hline $\begin{array}{l}\text { Baja inversión en obras públicas genera menor } \\
\text { consumo interno. }\end{array}$ & 0.06 & 3 & 0.18 \\
Alta rivalidad en la industria & 0.10 & 3 & 0.30 \\
Reacción de los competidores actuales. & 0.11 & 3 & 0.33 \\
Bajo costo de cambio hacia otros productos & 0.05 & 2 & 0.10 \\
Valor ponderado total & & & 3.22
\end{tabular}

Nota: David (2003)

Fuente: Elaboración propia

"Una Matriz de evaluación del factor externo (EFE) permite a los estrategas resumir y evaluar la información económica, social, cultural, demográfica, ambiental, política, gubernamental, legal, tecnológica y competitiva." (David, 2003, p. 110).

Para la matriz de evaluación del factor externo se identifica un resultado ponderado de 3.22 , por encima del valor promedio de 2.5 , lo cual nos indica que las estrategias de la empresa cuentan con buena capacidad de respuesta para tomar las oportunidades y reducir las amenazas a las que está expuesta.

Se ha considerado mayor valor a las referentes a la situación económica del Perú, la posición de los potenciales consumidores y la transformación digital.

Se aprecia que en la mayoría de los casos las estrategias de la empresa están en capacidad de aprovechar estas oportunidades dada su experiencia y posición global.

En el caso de las amenazas la rivalidad de la industria es alta y la reacción de los competidores muy fuerte. Se considera que las estrategias de la empresa para enfrentar estas amenazas están, en general, por sobre el promedio.

\subsection{Matriz de las Estrategias Genéricas}

"Una estrategia genérica de negocios da a una compañía una forma específica de posición competitiva y una ventaja frente a sus rivales que genera una rentabilidad superior al promedio." (Hill y Jones, 2009, p. 160).

La estrategia de negocio genérica que aplica la empresa para UNIQLO es Liderazgo en costos y diferenciación (estrategia combinada). 
Figura 2.1

Estrategia genérica

VENTAJA ESTRATEGICA

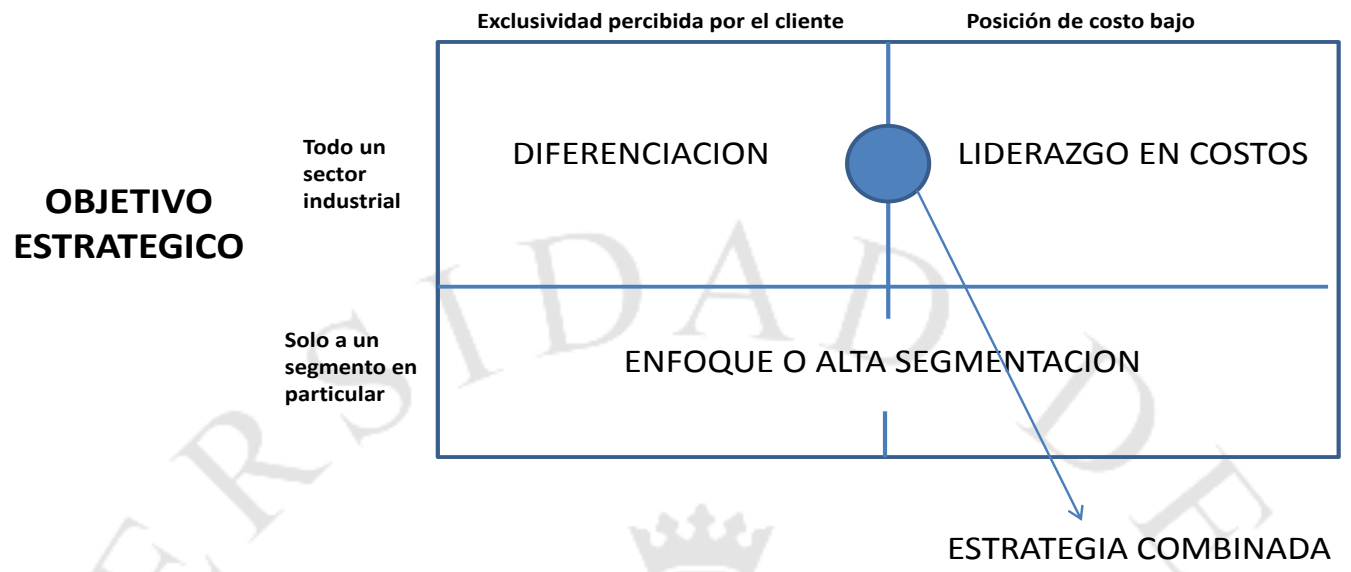

Nota: Hill y Jones (2009)

Fuente: elaboración propia

El liderazgo en costos sustentado por las economías de escala que obtiene a través de altos volúmenes de producción y de negociación con proveedores.

La diferenciación sustentada en confecciones que cuentan con características particulares de estilo, calidad y practicidad dirigida a diversos segmentos: damas, caballeros y niños.

\subsection{Matriz FODA}

Se consideran las fortalezas y debilidades identificadas y la propuesta de estrategias enfocadas al ingreso de UNIQLO al Perú.

La matriz de las amenazas, oportunidades, debilidades y fortalezas (FODA) es una herramienta de ajuste importante que ayuda a los gerentes a crear cuatro tipos de estrategias: estrategias de fortalezas y oportunidades (FO), estrategias de debilidades y oportunidades (DO), estrategias de fortalezas y amenazas (FA) y estrategias de debilidades y amenazas (DA). (David, 2003, p. 200). 


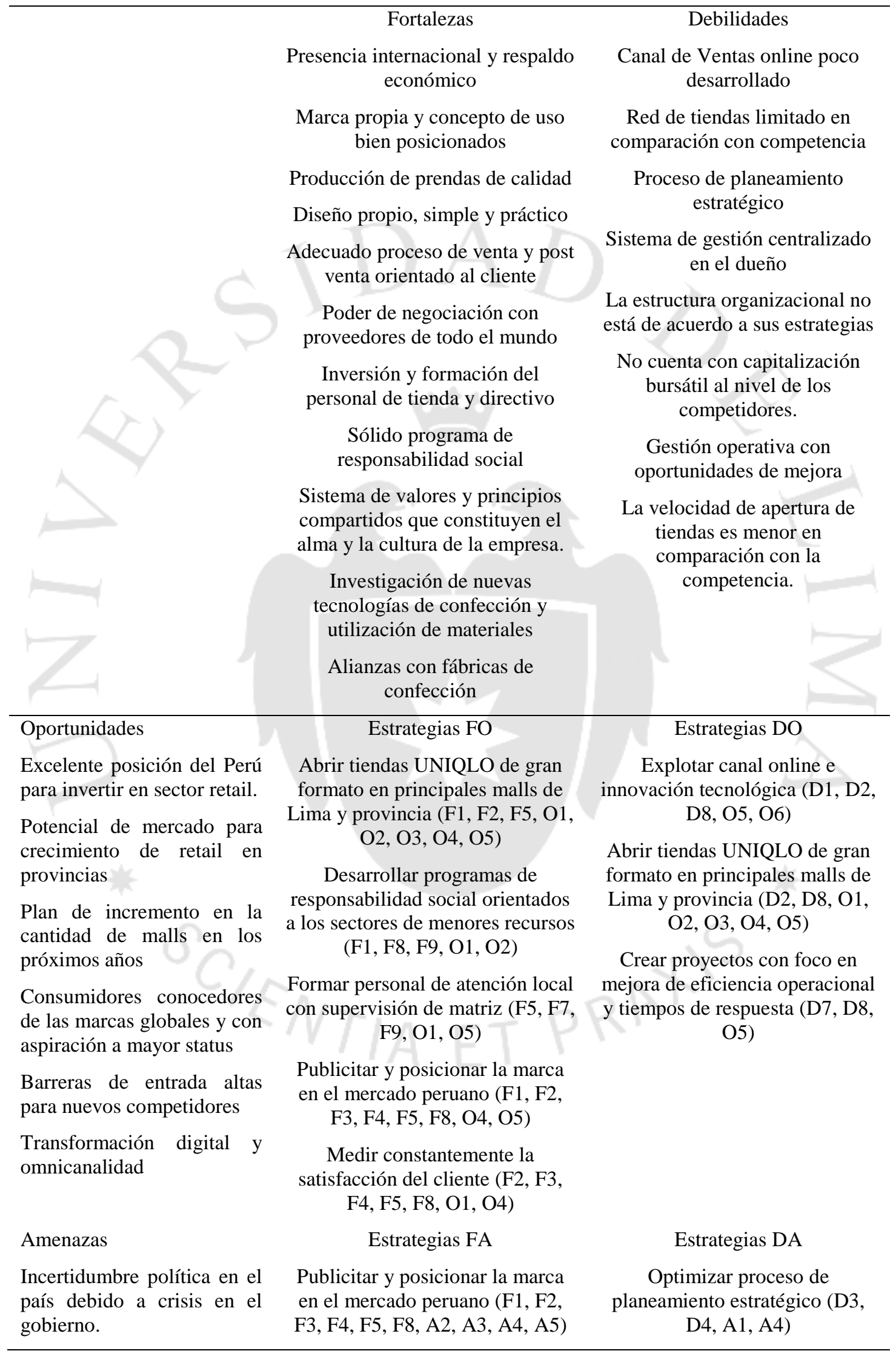




\begin{tabular}{|c|c|c|}
\hline $\begin{array}{l}\text { Baja inversión en obras } \\
\text { públicas genera menor } \\
\text { consumo interno. } \\
\text { Alta rivalidad en la industria }\end{array}$ & $\begin{array}{c}\text { Crear oferta de productos } \\
\text { diferenciada a costo asequible y } \\
\text { promociones (F3, F4, F5, F6, A3, } \\
\text { A4, A5) }\end{array}$ & $\begin{array}{l}\text { Crear proyectos con foco en } \\
\text { mejora de eficiencia operacional } \\
\text { (D7, D8, A3, A4, A5) }\end{array}$ \\
\hline $\begin{array}{l}\text { Reacción de los } \\
\text { competidores actuales. }\end{array}$ & $\begin{array}{l}\text { Desarrollar programas de } \\
\text { responsabilidad social orientados } \\
\text { a los sectores de menores recursos }\end{array}$ & \\
\hline Bajo costo de cambio hacia & $(\mathrm{F} 8, \mathrm{~A} 4, \mathrm{~A} 5)$ & \\
\hline otros productos & $\begin{array}{c}\text { Crear alianzas estratégicas con } \\
\text { malls y bancos (F1, F6, F11, A3, } \\
\text { A4) }\end{array}$ & \\
\hline & $\begin{array}{l}\text { Investigar uso de material / } \\
\text { insumos peruanos de calidad para } \\
\text { algunas de sus confecciones (F3, } \\
\text { F6, F10, A4) }\end{array}$ & \\
\hline
\end{tabular}

Nota: David (2003)

Fuente: Elaboración propia

Se puede apreciar que la empresa está en gran condición de desarrollar sus estrategias ya que cuenta con capacidades y competencias sólidas lo cual se sustenta en sus fortalezas, ventajas competitivas y posición global.

Se plantean 5 estrategias FO, 3 DO, 5 FA y 2 DA. El detalle de las estrategias que se proponen implementar se encuentra descrito en el acápite 2.8 .

\subsection{Definición y Sustentación de la Visión, Misión y Políticas}

\subsubsection{Visión}

La visión y misión de la empresa constituyen definiciones que le otorgan identidad y orientación a su gestión. Es el punto de partida de la planificación estratégica.

"La visión de una compañía expone cierto estado futuro deseado; expresa, con frecuencia a grandes rasgos, lo que la compañía trata de alcanzar" (Hill y Jones, 2009, p. 14).

La empresa no presenta una Visión definida como tal sino más bien una declaración corporativa en el contexto de su filosofía corporativa al estilo Fast Retailing: "Cambiando la ropa. Cambiando las creencias convencionales. Cambiamos el mundo." (Takeuchi, 2012, p. 23).

Esta declaración cumple con las características de una visión ya que responde a la pregunta ¿qué queremos llegar a ser? y se constituye como un desafío a largo plazo. 


\subsubsection{Misión}

"La misión describe qué hace la compañía" (Hill y Jones, 2009, p. 11). En el contexto del caso se define como:

"Crear ropa excelente con un valor nuevo y exclusivo, y permitir a las personas de todo el mundo experimentar la alegría, la felicidad y la satisfacción de poder ponérsela." (Takeuchi, 2012, p. 23).

"Enriquecer la vida de las personas mediante nuestras actividades corporativas exclusivas, y hacer crecer y desarrollar nuestra compañía en línea con la sociedad" (Takeuchi, 2012, p. 23).

La misión responde a la pregunta ¿cuál es la razón de ser? y se constituye como el eje de su filosofía de hacer negocios la cual articula los conceptos de innovación de la mano con el desarrollo de la sociedad. Está centrada en las personas y su bienestar.

Dado que la empresa es global se considera que tanto la Declaración corporativa como la misión permanecen únicas a nivel de todas las empresas del grupo.

\subsubsection{Políticas}

Las políticas de la empresa son los lineamientos o pautas definidas por la alta gerencia para el cumplimiento de los objetivos e implementación de las estrategias.

Las principales políticas de la empresa son las siguientes:

- Crecer a nivel global

- Obtener la máxima satisfacción de los clientes

- Formar y desarrollar al personal de la empresa

- Generar economías de escala

- Producir prendas de alta calidad

- Aportar a la generación de rentabilidad y eficiencia.

- Innovación permanente en diseño y utilización de materiales

- Desarrollar y potenciar la experiencia de venta y la post venta

- Conducir los negocios bajo principios éticos.

- Flexibilidad para adecuarse a los cambios 


\subsection{Definición de los Objetivos Estratégicos de la Empresa}

Se definen como objetivos estratégicos de la empresa en Perú los siguientes:

Posicionamiento de la marca y filosofía UNIQLO en el mercado peruano. - A fin de consolidar el conocimiento de la marca, su concepto de uso, los productos, servicio y el desarrollo de la sociedad que va ligado al concepto del negocio.

Consolidación en el tercer lugar de participación de mercado en el mediano plazo. - Se determina con la posición que desea obtener la empresa en su desarrollo en el mercado peruano.

Óptima satisfacción del cliente por la calidad de las prendas y servicio en tienda. - Se considera como objetivo prioritario dado que es uno de los elementos diferenciadores de UNIQLO que se deberá implementar y evaluar constantemente.

Contar con personal de ventas y administración altamente capacitado. - Es uno de los pilares del modelo de negocio de la empresa a nivel global potenciar y desarrollar al personal para la consecución de los objetivos de la empresa.

Estar considerada entre las 10 mejores empresas para trabajar (Great place to work, GPTW) en el mediano plazo. - El posicionamiento como un buen empleador se considera como aspecto clave para reforzar su imagen de empresa con excelente clima laboral.

Rentabilidad de la empresa según planes de casa matriz. - Principal indicador financiero que determina el rendimiento sobre el patrimonio. (ROE)

Generar utilidades según planes de casa matriz. - En concordancia con las metas de incrementar las ventas e ingresos a nivel global hacia el 2020.

Adecuada rotación de inventarios en tiendas. - Se constituye como un objetivo clave que permitirá reducir costos y generar eficiencia operacional.

Cumplir el plan de apertura de tiendas en el país. - Como parte del programa de expansión global en Sudamérica y de operaciones en Perú.

Establecer mejoras continuas a los procesos internos claves. - Para promover mejoras que aseguren reducciones de tiempos y costos con impacto en mantener o perfeccionar las ventajas competitivas de la empresa. 
Implementar canal online corporativo. - Para ir en concordancia con los canales corporativos y las tendencias tecnológicas presentes y futuras.

\subsection{Redefinición o creación de nuevas UEN}

Las unidades estratégicas de negocios actuales de la empresa Fast Retailing son:

- UNIQLO: que comprende UNIQLO Japón y UNIQLO Internacional.

- Marcas globales: comprendidas por Theory, Comptoir des Cotonnieres, Princesse Tam Tam.

- Marcas nacionales: GU, Shoes.

Se considera que para la entrada de la empresa en el Perú no amerita una redefinición o creación de UEN ya que la estrategia que se propone es el ingreso de la marca UNIQLO.

\subsection{Propuesta y sustentación de Estrategias en el ambiente Global, Corporativas,}

\section{de Negocios y Funcionales.}

\subsubsection{Estrategia en el ambiente global}

La estrategia es Global dado que la empresa usa su posición global para reducir costos a través de economías de escala y el poder de negociación con proveedores logrando de esta forma vender más barato que la competencia local. No se evidencia una adaptación local en los países en los que opera.

\subsubsection{Estrategias Corporativas}

Al contar con un modelo de negocio global las estrategias corporativas de integración o diversificación se generan desde la matriz.

Para el caso del ingreso al Perú se plantean las alianzas estratégicas. "Una alianza estratégica es una estrategia popular que ocurre cuando dos o más empresas integran una asociación o consorcio temporal con el propósito de aprovechar alguna oportunidad" (David, 2003, p. 177).

Estas alianzas serán con los propietarios de malls a fin de poder alquilar locales compartiendo costos e ingresos con las tiendas UNIQLO. Asimismo, establecer alianza con un banco líder a fin de ofrecer descuentos especiales y acumulación de millas e incluso generar, en el mediano plazo, una tarjeta de crédito de marca compartida. 
De otro lado se plantea el outsourcing para funciones no principales del negocio como son el soporte tecnológico a usuarios, selección de personal y manejo de cajas según se menciona más adelante en el desarrollo de las estrategias funcionales.

\subsubsection{Estrategias de negocios}

Como estratégica genérica de negocio se mantiene la estrategia combinada de liderazgo en costos y diferenciación que desarrolla la empresa a nivel mundial.

Asimismo, se recomienda llevar a cabo estrategias intensivas de penetración de mercado para los productos de la empresa en concordancia con su ingreso en el país.

Posteriormente en el mediano plazo realizar estrategia de desarrollo de mercado para su ingreso a las provincias donde se cuente con mayor consumo retail y existencia de malls. El detalle estas estrategias las mencionamos en el desarrollo de estrategias funcionales.

\subsubsection{Estrategias funcionales}

Se establecen para apoyar la estrategia de negocio de la empresa desde cada área funcional. Se plantean como principales las siguientes:

\section{Operaciones. -}

- Implementar la apertura de tiendas en el país según especificaciones de layout y oferta de productos establecidos por la matriz.

- Establecer indicadores de procesos, identificar e implementar mejoras con impacto en eficiencia.

- Documentar y actualizar procesos, políticas, funciones y protocolos en manuales a disposición del personal.

- Establecer mecanismos de despacho y puntos de recojo de mercadería vendida en canal on line.

- Control automatizado de inventarios y gestión de almacenes.

- Abastecimiento de efectivo de cajas con soporte de empresa especializada.

- Implementar máquina dispensadora de ropa Uniqlo to Go en el aeropuerto de Lima y Cusco. 
Marketing. -

- Realizar campañas de publicidad de impacto a través de medios tradicionales y digitales apoyándose en las campañas corporativas.

- Investigación de mercado y competencia a través de empresa especializada

- Definir promociones en tiendas y en canal on line. Descuentos por primera compra, cierra puertas, cuponera de descuentos, entre otros.

- Implementar programas de fidelización en coordinación con aliados.

- Contratar empresa que mida periódicamente la satisfacción del cliente.

- Conocer al consumidor en sus preferencias y comportamiento de compra.

- Realizar alianzas comerciales con banco líder para ofrecer beneficios a clientes comunes e implementar tarjeta de crédito de marca compartida en el mediano plazo.

Recursos humanos

- Contratar empresa externa para selección de personal.

- Implementar y mantener programas de capacitación del personal según lineamientos de matriz.

- Desarrollar programas de responsabilidad social en beneficio de las poblaciones de escasos recursos o afectadas por fenómenos naturales.

- Implementar la gestión por desempeño a fin de medir objetivamente el cumplimiento de las metas individuales de los empleados.

- Coordinar participación de la empresa en el reconocimiento Great place to work.

- Coordinar participación de líderes en el FRMIC a nivel global.

- Asegurar la contratación de un porcentaje de personal con discapacidad.

- Establecer programas de reconocimiento al personal. (ranking, incentivos)

Investigación y desarrollo

- Aportar a los centros de I+D de la empresa evaluando el uso de materiales peruanos, como algodón pima o lana de alpaca, en la confección de prendas.

\section{Sistemas}

- Tercerización de soporte tecnológico a usuarios. 
- Soporte directo en funcionamiento de sistema de ventas de tiendas, canal online y web.

- Explotación de bases de datos e información de gestión para el negocio.

- Desarrollos y ajustes puntuales a los sistemas y transformación digital según pautas de la matriz.

Ventas

- Supervisar proceso y protocolo de venta en tienda según estándares de la matriz.

- Asesoría permanente a los clientes en sus consultas de compra.

- Definir y monitorear metas de ventas semanales.

- Establecer relaciones con los clientes y venta cruzada de productos.

- Implementar ranking de mejores vendedores basado en cumplimiento de metas y calificación de clientes.

- Administrar la post venta centrada en satisfacer al cliente en sus requerimientos o reclamos. Medir tiempos de respuesta. 


\section{CAPÍTULO III: IMPLEMENTACIÓN ESTRATÉGICA}

\subsection{Evaluación del rediseño o no rediseño de la estructura organizacional de la empresa}

La estructura organizacional constituye uno de los pilares de la implementación de las estrategias ya que asegura la asignación de recursos y establece las líneas de autoridad y coordinación necesarias para la ejecución de las funciones que se designan a las áreas para la consecución de objetivos.

En ese sentido se identifica que existen oportunidades de mejora a fin de alinear la estructura a la estrategia de la empresa considerando además su ingreso al mercado peruano.

La estructura organizacional propuesta considera áreas corporativas que brindan soporte y directrices a la empresa y sus unidades de negocio:

Administración y Finanzas. - Área a cargo del planeamiento estratégico, contabilidad y finanzas.

Sistemas. - Área que brinda soporte en desarrollo de aplicaciones, canales digitales, continuidad operativa, seguridad informática.

Recursos humanos. - Área encargada de los procesos de selección, capacitación, remuneraciones, clima laboral, gestión de desempeño y responsabilidad social.

FRMIC. - Área encargada del proceso de formación de líderes. Por la relevancia y dirección a cargo del CEO se le considera como reporte directo en primera línea.

Compras. - Área corporativa que centraliza las adquisiciones al por mayor de las unidades de negocio a fin de obtener economías de escala para las Unidades estratégicas de negocio.

De otro lado tenemos las unidades estratégicas de negocio que reportan al CEO:

- UNIQLO

- Marcas Globales (Theory, Comptoir des Cotonnieres, Princesse Tam Tam)

- Marcas Nacionales (GU, Shoes) 
Unidad estratégica de negocio UNIQLO:

Producción. - Área encargada de coordinar con las fábricas asociadas la confección de prendas, control de calidad y asesoría técnica.

Investigación y desarrollo (I+D). - Área especializada en innovar diseños, materiales, canales digitales y alternativos.

Marketing. - Área a cargo de la publicidad, promoción, oferta de productos, fidelización y alianzas comerciales.

Ventas. - Área encargada de las ventas en tiendas y por medios digitales. Asimismo, de administrar la post venta.

América. - Unidad encargada de la gestión de tiendas en su región. Cuenta con equipos locales de Operaciones, Finanzas, Marketing, RRHH, Ventas y Sistemas. Reporta funcionalmente a Marketing y Ventas de la corporación.

Asia. - Unidad encargada de la gestión de tiendas en su región. Cuenta con equipos locales de Operaciones, Finanzas, Marketing, RRHH, Ventas y Sistemas. Reporta funcionalmente a Marketing y Ventas de la corporación.

Europa. - Unidad encargada de la gestión de tiendas en su región. Cuenta con equipos locales de Operaciones, Finanzas, Marketing, RRHH, Ventas y Sistemas. Reporta funcionalmente a Marketing y Ventas de la corporación.

Ventajas de la estructura organizacional propuesta

- La estructura facilita la gestión y coordinación en cada unidad de negocio enfocándose en la implementación de estrategias diferenciadas.

- Se cuenta con una estructura corporativa que define las pautas, políticas y buenas prácticas para toda la empresa y sus unidades de negocio.

- Se generan equipos locales para la gestión en cada país con reporte funcional a las unidades de Marketing y Ventas de la matriz lo cual asegura el alineamiento a las metas, estrategias y políticas comerciales de la Unidad estratégica de negocio UNIQLO. 
Figura 3.1

Estructura Organizacional propuesta de Fast Retaling

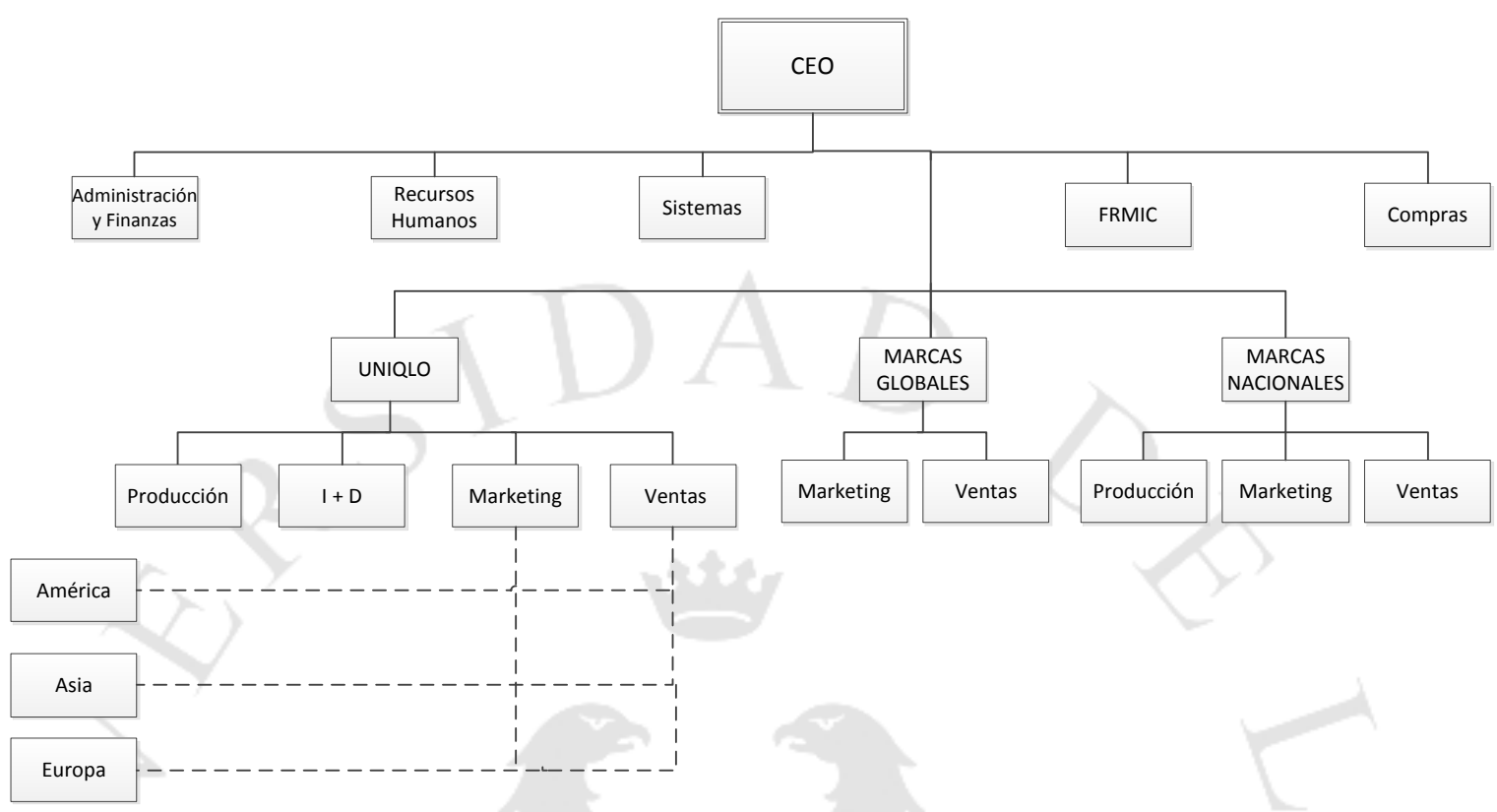

Fuente: Elaboración propia

\subsection{Propuesta de cambios para mejorar la implementación de estrategias en la} empresa.

La implementación de estrategias requiere de la ejecución de varias acciones a fin de asegurar su difusión, entendimiento, compromiso, puesta en marcha y control.

Los factores a tener en cuenta en la implementación son las personas, sistemas de dirección, áreas clave y estructura organizacional.

Personas. - Contar con el personal idóneo adecuadamente seleccionado, capacitado y permanentemente informado de los avances de las implementaciones. Se hace participar al personal clave en el proceso de definición y de implementación logrando su compromiso. Se reconocen sus aportes en el proceso de implementación.

Sistemas de dirección. - La cultura organizacional homogénea y compartida facilita la acción coordinada del personal hacia los objetivos de la empresa y por tanto la implementación de estrategias. 
Los conceptos de visión, misión, valores y principios de gestión de la empresa han sido debidamente definidos, difundidos e interiorizados al personal. De la misma manera se deberá realizar para las nuevas operaciones que iniciarán en el país.

El estilo de liderazgo es reconocido por ser participativo centrado en desarrollar a los empleados mediante entrenamiento y toma de decisiones. Se deberá aplicar un programa de liderazgo local que respete los principios corporativos, promueva la autonomía, la motivación, la comunicación y el aprendizaje.

Asimismo, se considera relevante para este factor:

- La participación del personal clave en el proceso de planificación estratégica y de las gerencias en el proceso de implementación logrando de esta manera equilibrar el proceso y generar compromiso de las partes.

- Crear canales de comunicación permanente sobre los objetivos y avances de los planes. Asimismo, línea abierta para consultas e inquietudes del personal.

- Adecuada gestión del cambio a fin de asegurar la difusión y el entendimiento de las estrategias y como benefician a la empresa y al mismo empleado.

- Desarrollar acciones de soporte a equipos y coaching que minimicen los conflictos y resistencia al cambio.

Ejecutar un plan de reconocimiento e incentivos por cumplimiento de objetivos e implementaciones exitosas.

Áreas claves. - Son Ventas, Recursos Humanos, Marketing, Operaciones y Sistemas. Estas áreas deberán contar con los recursos humanos, materiales, económicos y tecnológicos necesarios para implementar las estrategias funcionales que desarrollarán en el Perú según se ha definido en el acápite 2.8.

La gerencia de América que reporta a la Unidad estratégica de negocio UNIQLO cumple un rol relevante ya que deberá orquestar todos los elementos a fin de lograr una implementación adecuada. Propondrá el ingreso de la empresa al Perú mediante alianzas estratégicas según lo descrito en el acápite 2.8 de estrategias funcionales. 
Se deberá centrar en definir objetivos de corto plazo, políticas específicas, asegurar la distribución de recursos, promover la adaptación de procesos internos. Liderará las comunicaciones y el sistema de dirección en general.

Se apoyará en reuniones periódicas de seguimiento con los líderes de cada frente a fin de revisar los cronogramas, avances, logros, riesgos y próximas acciones.

Estructura Organizacional. - La nueva estructura planteada responde a las estrategias y está alineada a los objetivos, áreas clave y ventajas competitivas de la empresa.

Deberá ser adecuadamente difundida y se realizarán capacitaciones a fin de explicar los cambios y la asunción de nuevas funciones.

Se documentará la estructura y sus funciones en un manual a disposición del personal. Asimismo, se documentarán los procesos y procedimientos que desarrollan las áreas a fin de contar con un soporte adecuado en la realización de sus actividades.

Este conjunto de factores con las acciones planteadas asegura un equilibrio entre las funciones administrativas lo cual soportará la exitosa implementación de las estrategias para Fast Retailing en Perú. 


\section{CAPÍTULO IV: CONTROL ESTRATÉGICO}

\subsection{Diseño de un Mapa Estratégico de Control para la empresa}

"El mapa estratégico representa la relación de causa-efecto que hay entre los objetivos trazados y los temas estratégicos. Cuando estas relaciones están claramente definidas, se puede comunicar y delegar las responsabilidades en forma efectiva." ("Qué es un mapa estratégico y qué utilidad tienen en la organización”, 2017, párr.4)

Se plantea el siguiente mapa considerando los objetivos estratégicos definidos para la empresa en Perú.

Figura 4.1

Mapa Estratégico de Control para la empresa

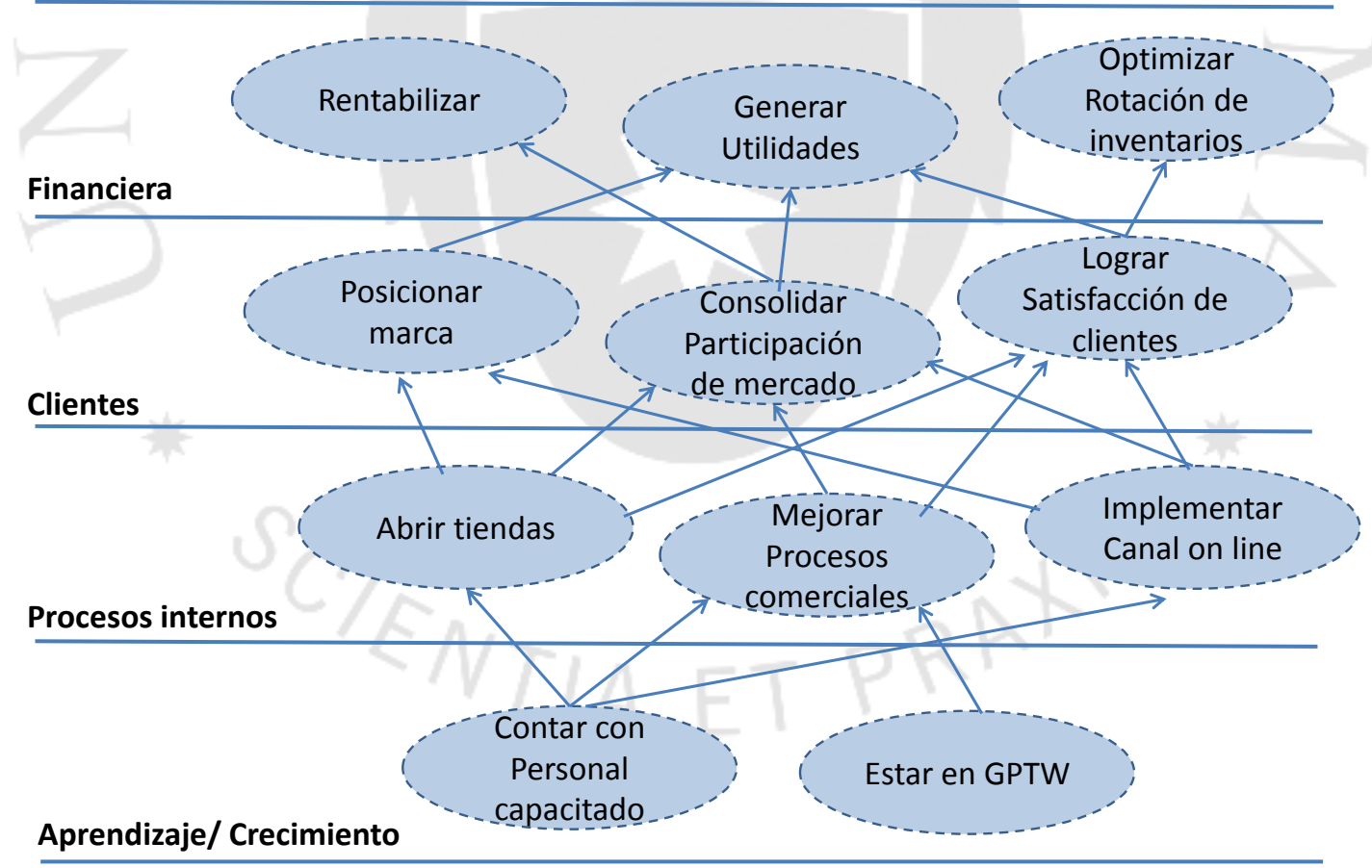

Nota: Conexión Esan (2017)

Fuente: Elaboración propia 


\subsection{Desarrollo de un Cuadro de Mando Integral con un mínimo de 10 índices de gestión}

El BSC o CMI se apoya en diversos indicadores que permiten vincular los objetivos de la empresa con planes de acción concretos. Mediante los indicadores, el BSC puede controlar y monitorear tanto los objetivos de las empresas como las diferentes áreas de negocio. ("El Balance

Scorecard y sus cuatro grupos de indicadores”, 2016, párr.3)

El cuadro de mando integral propuesto considera los objetivos estratégicos y sus indicadores definidos para las operaciones de la empresa en el Perú.

Será actualizado periódicamente con la información disponible de resultados a fin de realizar la comparación con las metas establecidas para cada indicador.

Los resultados y semáforo del cuadro de mando integral deberán ser presentados a las gerencias en forma mensual y difundidos al personal responsable de su ejecución.

Se tomarán las medidas necesarias para realizar ajustes o acciones correctivas que permitan llegar a los objetivos en forma satisfactoria.

La evaluación del personal también estará en función al cumplimiento de objetivos del cuadro de mando integral para lo cual se trasladarán, los que apliquen, a su gestión de desempeño individual.

El cuadro de mando integral para la empresa Fast Retailing en Perú es el siguiente:

Tabla 4.1

Cuadro de mando integral para la empresa Fast Retailing en Perú

\begin{tabular}{|c|c|c|}
\hline Perspectiva & Objetivo & Índice de gestión \\
\hline \multirow[t]{3}{*}{ Financiera } & $\begin{array}{c}\text { Rentabilizar la empresa según } \\
\text { planes de casa matriz }\end{array}$ & $\begin{array}{c}\text { ROE: Utilidad neta/ patrimonio } \\
\text { neto }\end{array}$ \\
\hline & $\begin{array}{c}\text { Generar utilidades según planes } \\
\text { de casa matriz }\end{array}$ & Utilidades en US\$ \\
\hline & $\begin{array}{l}\text { Optimizar rotación de } \\
\text { inventarios en tiendas }\end{array}$ & Costo de Ventas/ Inventarios \\
\hline \multirow[t]{2}{*}{ Clientes } & $\begin{array}{l}\text { Consolidar en el tercer lugar de } \\
\text { participación de mercado en el } \\
\text { mediano plazo }\end{array}$ & $\begin{array}{l}\text { Número de Posición en el } \\
\text { mercado }\end{array}$ \\
\hline & $\begin{array}{l}\text { Lograr la óptima satisfacción del } \\
\text { cliente por la calidad de las }\end{array}$ & $\%$ de satisfacción de cliente en \\
\hline
\end{tabular}




\begin{tabular}{|c|c|c|}
\hline & prendas y servicio en tienda & encuestas \\
\hline & $\begin{array}{l}\text { Posicionar la marca y filosofía } \\
\text { UNIQLO en el mercado peruano }\end{array}$ & $\begin{array}{l}\text { Posición en ranking de } \\
\text { recordación de marca. }\end{array}$ \\
\hline \multirow[t]{4}{*}{ Procesos internos } & $\begin{array}{l}\text { Cumplir el plan de apertura de } \\
\text { tiendas en el país }\end{array}$ & $\begin{array}{c}\text { Cantidad de tiendas abiertas en } \\
\text { el año }\end{array}$ \\
\hline & Mejorar procesos comerciales & $\begin{array}{l}\% \text { de reducción de tiempos de } \\
\text { atención }\end{array}$ \\
\hline & & $\begin{array}{c}\% \text { de Reducción de costo de } \\
\text { venta }\end{array}$ \\
\hline & $\begin{array}{l}\text { Implementar canal online } \\
\text { corporativo }\end{array}$ & $\begin{array}{l}\text { Numero de compras online/ } \\
\text { Número de compras totales }\end{array}$ \\
\hline \multirow[t]{2}{*}{$\begin{array}{l}\text { Aprendizaje/ } \\
\text { crecimiento }\end{array}$} & $\begin{array}{c}\text { Contar con personal de ventas y } \\
\text { administración altamente } \\
\text { capacitado }\end{array}$ & $\begin{array}{c}\text { Cantidad de horas de } \\
\text { capacitación por persona en el } \\
\text { año }\end{array}$ \\
\hline & $\begin{array}{c}\text { Estar entre las mejores empresas } \\
\text { para trabajar (GPTW) en el } \\
\text { mediano plazo }\end{array}$ & $\begin{array}{l}\text { Número de posición en encuesta } \\
\text { GPTW }\end{array}$ \\
\hline
\end{tabular}

Nota: Conexión Esan (2016)

Fuente: Elaboración propia

Los índices que se plantean para medir el cumplimiento de los objetivos son los siguientes:

Perspectiva Financiera

ROE.-. Indica el rendimiento del capital invertido por los accionistas.

Utilidades en US\$. - Indica el monto de utilidades planificados por la matriz.

Costo de Ventas/ Inventarios. - Indica la eficiencia del uso de los inventarios.

\section{Perspectiva Clientes}

Número de Posición en el mercado. - Indica la ubicación de la empresa en el mercado peruano.

$\%$ de satisfacción de cliente en encuestas. - Indica que tan satisfechos están los clientes con los productos, servicio y canales de atención.

Posición en recordación de marca. - Indica el nivel de recordación de la marca global, concepto de uso de prendas y actividades de responsabilidad social de la empresa. 
Perspectiva Procesos internos

Cantidad de tiendas abiertas en el año. - Indica el número de tiendas que inician operaciones en el año.

$\%$ de reducción de tiempos de atención. - Indica en cuánto se logra reducir el tiempo de atención para los procesos de venta, colas en caja, arreglos, devoluciones, reclamos, entre otros

\% de Reducción de costo de venta. Indica en cuánto se reduce el costo de ventas por mejoras implementadas en los procesos como eliminar actividades redundantes o manuales, entre otros.

Numero de compras online/ Número de compras totales. - Indica el volumen transaccional de este canal en relación al total de compras realizadas por clientes.

Perspectiva Aprendizaje- Crecimiento

Cantidad de horas de capacitación por persona en el año. - Indica la cantidad de horas de capacitaciones internas y participación de personal clave en el FRMIC.

Número de posición en encuesta GPTW. - Indica la posición lograda en la encuesta de clima laboral a nivel nacional. 


\section{CONCLUSIONES}

- La marca global UNIQLO cuenta con una oferta de valor basada en confecciones básicas, combinables, de gran calidad e innovación a precios accesibles, con procesos de venta y post venta centrados en la satisfacción del cliente.

- El grupo Fast Retailing posee un modelo de negocio sólido y ventajas competitivas reconocidas en innovación, calidad, eficiencia operacional y satisfacción al cliente que lo sitúan en excelente posición para afianzar su expansión.

- El grupo es fuerte en generación de economías de escala a través de producción de altos volúmenes de prendas y la realización de compras de grandes cantidades de material. Esto aunado a su oferta de valor le permite establecer una estrategia genérica de negocio de diferenciación y liderazgo en costos (combinada).

- La filosofía corporativa de Fast retailing es compartida y está interiorizada por el personal de la empresa constituyéndose como un pilar fundamental de su gestión. Promueve la innovación y facilita la implementación de estrategias y gestión del cambio.

- El entorno en Perú presenta muy buenas perspectivas desde el punto de vista económico y de hábitos de consumo, aunque debe considerarse la alta rivalidad de la industria y la reacción de los competidores como amenazas que deben ser contrarrestadas.

- La competencia de UNIQLO está constituida por las Tiendas Zara y H\&M las cuales también se encuentran presentes en el mercado peruano. Se consideran también las tiendas por departamento principalmente Saga y Ripley. 


\section{RECOMENDACIONES}

- Iniciar operaciones en el mercado peruano en Lima y en el mediano plazo en las provincias donde se concentre mayor volumen de consumo retail y existencia de malls.

- Desarrollar estrategias corporativas orientadas a establecer alianzas estratégicas con propietarios de malls, bancos entre otros a fin de compartir costos e ingresos.

- Asimismo, considerar el outsourcing, para las actividades no principales del negocio, que permita reducir costos y enfocarse en generar mayores ventas.

- Desarrollar estrategias de negocio de penetración de mercado realizando acciones de marketing como campañas publicitarias, promociones y alianzas para ofrecer beneficios a los clientes, así como una tarjeta de crédito de marca compartida con un banco líder del sistema financiero.

- Desarrollar las siguientes estrategias funcionales con mayor prioridad:

- Establecer indicadores de procesos a fin de identificar e implementar mejoras con impacto en eficiencia.

- Soporte para abastecimiento de efectivo de cajas a través de empresa especializada.

- Incrementar canales a través de la implementación de máquinas dispensadoras de ropa "Uniqlo to Go" en los aeropuertos de Lima y Cusco.

- Realizar campañas de publicidad de impacto apoyándose en las que se definan a nivel corporativo.

- Realizar alianzas comerciales con banco líder para ofrecer beneficios a clientes comunes e implementar tarjeta de crédito de marca compartida en el mediano plazo.

- Desarrollar programas de responsabilidad social en beneficio de las poblaciones de escasos recursos o afectadas por fenómenos naturales.

- Definir la participación de la empresa en el reconocimiento Great place to work. 
- Asegurar la contratación de un porcentaje de personal con discapacidad.

- Aportar a los centros de I+D evaluando el uso de materiales peruanos en la confección de prendas.

- Tercerización de soporte tecnológico a usuarios.

- Generar la explotación periódica de bases de datos e información de gestión para el negocio.

- Asegurar el proceso y protocolo de venta en tienda según estándares de la matriz.

- Establecer relaciones con los clientes y venta cruzada de productos.

- Administrar la post venta a fin de satisfacer al cliente en sus requerimientos o reclamos.

- Establecer la estructura organizacional de la empresa por Unidades estratégicas de negocio lo cual facilitará la gestión con enfoque en la implementación de políticas diferenciadas y con soporte de áreas corporativas.

- Asegurar la adecuada implementación de las estrategias ejecutando las siguientes acciones con mayor prioridad:

- Participación del personal clave en el proceso de definición y de implementación logrando su compromiso. Reconocer sus aportes.

- Aplicar un programa de liderazgo local según la cultura corporativa que promueva la autonomía, la motivación y la comunicación.

- Crear canales de comunicación permanente de difusión de los planes y para consultas del personal.

- Adecuada gestión del cambio a fin de asegurar la difusión y el entendimiento de las estrategias y sus beneficios.

- Implementar reuniones periódicas de seguimiento con los líderes de cada frente a fin de revisar los cronogramas, avances, riesgos y acciones.

- Difundir la nueva estructura y realizar capacitaciones a fin de explicar los cambios y la asunción de nuevas funciones

- Documentar los procesos y procedimientos que desarrollan las áreas a fin de contar con un soporte adecuado en la realización de sus actividades 
- Realizar el control periódico de los indicadores del cuadro de mando integral coordinando los ajustes o medidas correctivas necesarias. Incorporar indicadores en la gestión de desempeño individual de los colaboradores. 


\section{REFERENCIAS BIBLIOGRÁFICAS}

Conexión Esan. (08 de setiembre de 2016). El Balance Scorecard y sus cuatro grupos de indicadores. Recuperado de https://www.esan.edu.pe/apuntesempresariales/2016/09/el-balanced-scorecard-y-sus-cuatro-grupos-deindicadores/

Conexión Esan. (20 de julio de 2017). Qué es un mapa estratégico y qué utilidad tiene en la organización. Recuperado de https://www.esan.edu.pe/apuntesempresariales/2017/07/que-es-un-mapa-estrategico-y-que-utilidad-tiene-en-laorganizacion/

David, F. R. (2003). Conceptos de Administración Estratégica ( $9^{\mathrm{a}}$ ed.). México: Pearson Educación.

ELLE España. (01 de septiembre de 2017). Uniqlo y Barcelona: una historia de amor. [archivo de video]. Recuperado de https://www.youtube.com/watch?v=SMM7uVXaKAE

Hill, C. W. y Jones, G. R. (2009). Administración Estratégica ( $8^{\mathrm{a}}$ ed.). México D.F.: Mc Graw Hill.

KPIX CBS SF Bay Area. (30 de julio de 2018). SFO Vending Machine Sells Jackets To Bay Area Summer Tourists. [archivo de video]. Recuperado de https://www.youtube.com/watch?v=1je1a5UuqJ8

Odriozola, A. (20 de septiembre de 2017). ¿Qué comprar en la marca japonesa de la que todo el // mundo habla? Recuperado de https://www.revistagq.com/moda/tendencias/articulos/uniqlo-espana-quecomprar/26698

Osterwalder, A. y Pigneur, Y. (2011). Generación de modelos de negocio. [versión pdf]. Recuperado de http://www.convergenciamultimedial.com/landau/documentos/bibliografia2016/osterwalder.pdf 
Takeuchi, H. (2012). Grupo Fast Retailing (caso 713 - S21). Recuperado del sitio de internet de Universidad Harvard, Escuela de Negocios: https://www.harvard.edu/

UNIQLO UK. (07 de enero de 2015). Ultra Light Down - The water defender. [archivo de video]. Recuperado de https://www.youtube.com/watch?v=KudCfygI5X8 